\title{
Components of the wall and capsule of Bacillus megaterium NCIB 7581
}

\author{
A. H. Bishop, † C. W. I. Douglas, $\ddagger$ P. K. DoRR§ and P. J. WhitE* \\ Department of Molecular Biology and Biotechnology, Firth Court, The University, Western Bank, \\ Sheffield S10 2UH, UK
}

(Received 11 December 1992; revised 26 April 1993; accepted 26 May 1993)

\begin{abstract}
Walls of Bacillus megaterium NCIB 7581 consisted principally of peptidoglycan $(55 \%, w / w)$ and a single acidic carbohydrate accessory polymer (about $30 \%, w / w)$, which was isolated from lysozyme-digests of the walls. Glucose and $\boldsymbol{N}$-acetylglucosamine partly made up this polymer, but phosphate and uronic or aminouronic acids were absent from the polymer and the wall. Protein (about $10 \%$, w/w) was present in the walls, even though incubation with trypsin was a step in their isolation. When released into solution, this protein gave a single band on gel-electrophoresis and could be digested by trypsin. The remainder of the material isolated as walls was poly $\beta$-hydroxybutyrate, which represented cytoplasmic contamination. Capsules were formed best by bacteria on solid media containing amino acids, at relatively low growth temperatures. The isolated capsular material was polypeptide.
\end{abstract}

\section{Introduction}

Bacillus megaterium NCIB 7581, when grown in a chemically defined medium, makes a wall that contains approximately $55 \%(\mathrm{w} / \mathrm{w})$ peptidoglycan, but which contains no phosphorus or uronic acid (White, 1977). Consequently, neither of the usual 'accessory polymers' of Gram-positive bacterial walls (teichoic and teichuronic acids) appear to be formed. The present paper describes an investigation of the non-peptidoglycan components of this wall. These have proved to be a weakly acidic polysaccharide and a protein, and there is some poly $\beta$ hydroxybutyrate, present as trapped cytoplasmic granular inclusions.

Under some conditions of growth, these organisms also form a capsule. This material is easier to isolate than the polysaccharide of the wall, and its chemical nature was first examined, with the hope that it might be the

*Author for correspondence. Tel. +44742768555 ; fax +44742 728679.

†Present address: Department of Biological and Chemical Sciences, University of Greenwich, Wellington Street, Woolwich, London SE18, UK.

$\ddagger$ Present address: Department of Oral Pathology, School of Clinical Dentistry, Claremont Crescent, Sheffield S10 2TA, UK.

§ Present address: Rhône Poulenc Agriculture Ltd, Fyfield Road, Ongar, Essex CM5 0HW, UK. same as the accessory polymer. However, the capsule was found to be a polypeptide.

\section{Methods}

Organisms. Bacillus megaterium NCIB 7581 is the wild-type parent strain [which needs biotin for growth in a minimal medium at $37^{\circ} \mathrm{C}$ (Al-ssum \& White, 1977)] of the diaminopimelate-requiring mutant SW1 (Saleh \& White, 1976) which lacks $N$-acetyl-LL-diaminopimelate deacetylase (Saleh \& White, 1979). Mutant GW1 is a double mutant (derived from SW1 by treatment with nitrosoguanidine) that requires lysine as well as diaminopimelate for growth and which lacks both diaminopimelate decarboxylase and the deacetylase. In the mutant, peptidoglycan may be specifically labelled with radioactive diaminopimelate, which is taken up readily from the medium. The wild-type was maintained on nutrient agar, and both mutants on nutrient agar plus synthetic 2,6-diaminopimelate (a mixture of the three isomers, $100 \mathrm{mg}^{-1}$ ). Cultures were incubated for $18 \mathrm{~h}$ at $37^{\circ} \mathrm{C}$ and then kept at $2{ }^{\circ} \mathrm{C}$. Viability of the wild-type and of the mutants decreases rapidly on longer incubation at $37^{\circ} \mathrm{C}$.

Media and conditions for growth. Liquid cultures were incubated at $37^{\circ} \mathrm{C}$ with shaking in the chemically defined medium $\mathrm{A}$ (White, 1972) containing biotin $\left(20 \mu \mathrm{g}^{-1}\right)$ and trisodium citrate dihydrate $\left(20 \mathrm{mg} \mathrm{l}^{-1}\right)$, with glucose $(1 \%, w / v)$ as major carbon source. For the mutants, diaminopimelate (synthetic, $100 \mathrm{mg} \mathrm{l}^{-1}$ ) alone or with L-lysine $\left(100 \mathrm{mg} \mathrm{l}^{-1}\right)$ was added as necessary.

For production of capsules, organisms were always grown on solid medium in Petri dishes. Nutrient agar or medium A (see Results) solidified with $1.5 \%(\mathrm{w} / \mathrm{v})$ agar was used.

Isolation of walls and sacculi. Walls were isolated from organisms harvested in the late exponential phase, as described by Day \& White (1977). Sacculi were made by addition of SDS to growing cultures, followed by washing and enzymic treatments, as described by White $\&$ Gilvarg (1977). Radioactive sacculi (doubly labelled) were made from 
mutant GW1 grown with $\left[{ }^{3} \mathrm{H}\right]$ diaminopimelate [mixed meso-, LL- and DD-isomers; $0.1 \mathrm{mg} \mathrm{ml}^{-1} ; 100 \mu \mathrm{Ci}(3.7 \mathrm{MBq})$ in $50 \mathrm{ml}$ of medium] and $\left[{ }^{14} \mathrm{C}\right.$ ]glucose [5 mg ml${ }^{-1} ; 25 \mu \mathrm{Ci}(0.93 \mathrm{MBq})$ in $50 \mathrm{ml}$ of medium].

Isolation of the acidic polymer. (a) Lysozyme-digestion of walls. To a suspension of walls $\left(5 \mathrm{mg} \mathrm{ml}^{-1}\right)$ in $0.1 \mathrm{M}$-ammonium acetate, $\mathrm{pH} 6.5$, plus $10 \mathrm{mM}-\mathrm{NaCl}$ was added lysozyme (final concentration $0.1 \mathrm{mg} \mathrm{ml}^{-1}$ ) and a few drops of toluene, then the mixture was incubated overnight at $37^{\circ} \mathrm{C}$ with shaking $\left(150\right.$ gyrations $\left.\min ^{-1}\right)$. Next, the suspension was centrifuged $(23000 \mathrm{~g}$ for $30 \mathrm{~min})$ and the supernatant liquid was freezedried. The solid was taken up in a minimum volume of water $(4 \mathrm{ml}$ or less) and was put onto a column of Sephadex G-200 $(2 \times 48 \mathrm{~cm})$ which had been equilibrated with the running buffer ( $50 \mathrm{~mm}$-ammonium acetate, $\mathrm{pH} 7$ ). Fractions were collected while elution proceeded with a flow rate of $9 \mathrm{ml} \mathrm{h}^{-1}$ and samples $(100 \mu)$ were assayed for hexoses (see below). The fractions that gave a positive result emerged as a single peak near the void volume of the column and were pooled and freezedried. The solid was again taken up in a small volume of water and was acidified to $\mathrm{pH} 2$ to 3 with $\mathrm{HCl}$. Ethanol (3.5 vols) was added and the resulting opaque liquid was left overnight at $2^{\circ} \mathrm{C}$ while a precipitate formed. Liquid was decanted, and the solid residue taken up in water and once more freeze-dried. This material was called 'lysozymeextracted polymer'.

(b) Extraction of walls with dilute acid. Walls (about $3 \mathrm{mg} \mathrm{ml}^{-1}$ ) were suspended in $0.1 \mathrm{M}-\mathrm{HCl}(15 \mathrm{ml})$ in a sealed glass tube and gently shaken for $24 \mathrm{~h}$ at $60^{\circ} \mathrm{C}$, then the solid residue was removed by centrifuging at $26000 \mathrm{~g}$ for $30 \mathrm{~min}$. The supernatant liquid was freeze-dried, and termed 'mild acid extracted polymer'. The solid residue (from acidextraction) was $N$-acetylated (Hayashi et al., 1973) and dialysed against four changes of water at $4{ }^{\circ} \mathrm{C}$ to yield 'high mol. mass $N$-acetylated peptidoglycan' which was freeze-dried.

(c) From radioactive sacculi. Procedure was the same as in (a) above except that fractions from the Sephadex G-200 column were monitored by liquid scintillation counting of samples from selected fractions. Fractions making up the first radioactive peak were pooled and freezedried, and the whole process of gel chromatography was repeated twice more with high mol. mass pooled material. The fractions that gave the first peak of radioactivity in the last separation were combined, freezedried and precipitated from acid solution by ethanol as described in $(a)$ above.

Titration of the polymer. A solution ( $7 \mathrm{ml}$ ) of the lysozyme-extracted polymer $\left(5 \mathrm{mg} \mathrm{m}^{-1}\right)$ in distilled water had an initial $\mathrm{pH}$ value of 3.0 . Small volumes of $0.1 \mathrm{M}-\mathrm{NaOH}(10$ to $100 \mu$ depending on the slope of the titration curve at the point of addition) were added from a micropipette while the solution was stirred continuously and the $\mathrm{pH}$ value was monitored. In the same way, another similar solution of the polymer was titrated from $\mathrm{pH} 3$ to lower values with $0 \cdot 1 \mathrm{M}-\mathrm{HCl}$.

Isolation of capsular material. (a) Capsulated organisms were broken at $2{ }^{\circ} \mathrm{C}$ by passage of a suspension (about $10 \mathrm{mg}$ dry wt $\mathrm{ml}^{-1}$ ) at $140 \mathrm{MPa}$ through a pressure cell (Milner et al., 1950). The solid fragments were centrifuged, and washed once with water; by phasecontrast microscopy, capsular material could still be seen attached. After digestion with lysozyme (as above) the undissolved residue was centrifuged and washed twice with water. When some of this material was suspended in Indian ink and viewed by phase-contrast microscopy large bright amorphous clumps were seen.

(b) Capsulated organisms were suspended in $5 \mathrm{ml}$ of sterile saline (to about $20 \mathrm{mg}^{\mathrm{dry} \mathrm{wt} \mathrm{m}}{ }^{-1}$ ) and were taken up and squirted 20 times through a needle on a syringe. The suspension was then centrifuged and the supernatant liquid kept. This was opalescent, but no bacteria could be seen microscopically. Addition of $2 \mathrm{M}-\mathrm{H}_{2} \mathrm{SO}_{4}$ (two drops) and ethanol (about $20 \mathrm{ml}$ ) led to formation of a white precipitate, which was collected. Similar treatment of uncapsulated organisms produced no opalescence in the supernatant liquid obtained after syringing, and no precipitate from this liquid was formed by acidified ethanol.
Paper chromatography. All chromatograms were developed with descending solvents on Whatman no. 1 paper. The solvents were (all parts by vol.): A, propan-1-ol/pyridine/acetic acid/water $(8: 8: 2: 4)$; B, acetone/acetic acid/water $(6: 2: 2) ; \mathrm{C}$, butan-1-ol/pyridine/water (6:4:2); D, butan-1-ol/acetic acid/water (5:1:2); E, ethyl acetate/ pyridine/water $(36: 10: 11.5) ; \mathrm{F}$, methanol/pyridine/ $11.6 \mathrm{M}-\mathrm{HCl} /$ water $(40: 5: 1 \cdot 25: 9)$. Reagents used to show positions of compounds on the chromatograms were: ninhydrin ( $0.1 \%$ in acetone) followed by heating for $5 \mathrm{~min}$ at $80^{\circ} \mathrm{C}$ for amino acids and amino sugars; $p$-anisidine $[3 \%$, $\mathrm{w} / \mathrm{v}$, in butan-1-ol/ethanol/water ( $4: 1: 1$, by vol.) with a few crystals of stannous chloride], followed by heating as above; or $\mathrm{AgNO}_{3}-\mathrm{NaOH}$ as described by Bailey (1969) to detect reducing sugars and their derivatives; bromophenol blue (40 mg in $95 \%, \mathrm{v} / \mathrm{v}$, aqueous ethanol, adjusted to $\mathrm{pH} 6.5$ ) for acids, which appeared as yellow spots against a blue background.

Gel electrophoresis. Electrophoresis in the presence of SDS was done by the method of Laemmli (1970), using $10 \%(w / v)$ polyacrylamide gels. Gels were fixed and stained in one step by immersion in $0.2 \%$ Coomassie Brilliant Blue in acetic acid/ethanol/water $(10: 45: 45$, by vol.) and de-stained in a similar solvent mixture but using methanol instead of ethanol. In some experiments gels were silver stained by the method of Morrissey (1981). Protein mol. mass standards (Sigma) were included on each gel and consisted of carbonic anhydrase $(29000 \mathrm{Da})$, egg albumin $(45000 \mathrm{Da})$, bovine albumin $(97400 \mathrm{Da}), \beta$-galactosidase $(116000 \mathrm{Da})$ and myosin $(205000 \mathrm{Da})$.

Chemical analyses. In order to dissolve the granules of poly $\beta$ hydroxybutyrate, a known weight of walls was sedimented from aqueous suspension and taken up in 2-methoxyethanol (which is miscible with water and with chloroform), then again centrifuged; the pad was suspended in chloroform $(5 \mathrm{ml})$ and kept at $55^{\circ} \mathrm{C}$ for $5 \mathrm{~min}$; after cooling, ethanol $(5 \mathrm{ml})$ was added (to lower the fluid density so that the walls could be sedimented), the walls were spun down and the supernatant liquid (extract) was kept; extraction of the walls with hot chloroform was done twice more, then the volume of the combined chloroform/ethanol extracts was made up (with chloroform) to $30 \mathrm{ml}$. Poly $\beta$-hydroxybutyrate in dried samples of this extract was measured as described by Herbert et al. (1971), with sodium 3-hydroxybutyrate as standard. To recover the walls free of granules, the pad (from the third centrifuging from chloroform/ethanol) was washed in 2methoxyethanol and then repeatedly in water.

Diaminopimelic acid was measured in acid hydrolysates $(6 \mathrm{M}-\mathrm{HCl}$ for $18 \mathrm{~h}$ at $105^{\circ} \mathrm{C}$ ) by reaction with acidic ninhydrin at $37^{\circ} \mathrm{C}$ (Work, 1957).

Sugars were measured with the phenol/sulphuric acid method [using $5 \%(\mathrm{w} / \mathrm{v})$ phenol] of Dubois et al. (1956). Pentoses, 6-deoxyhexoses and uronic acids also react in this assay but none of these latter compounds have been found in the walls. Hexoses were also sometimes measured with the anthrone procedure described by Herbert $e t$ al. (1971). Glucose was assayed enzymically in acid hydrolysates (1 or $2 \mathrm{M}$ $\mathrm{HCl}$ for $1 \mathrm{~h}$ at $100^{\circ} \mathrm{C}$ ) as described by Bergmeyer \& Bernt (1963). Galactose was also estimated in these hydrolysates, using the enzymic test kit from Worthington. Hexosamines were measured in acid hydrolysates $\left(3 \mathrm{M}-\mathrm{HCl}\right.$ for $3 \mathrm{~h}$ at $\left.100^{\circ} \mathrm{C}\right)$ by several procedures: that of Levvy \& McAllan (1959), in which muramic acid and glucosamine (after $N$-acetylation) give similar yields of coloured product per $\mu \mathrm{mol}$; that of Cessi \& Piliego (1960) which can be made specific for glucosamine or for galactosamine; and that of Stewart-Tull (1968) in which glucosamine and muramic acid can be separately assessed. Assays for uronic acids (Bitter \& Muir, 1962) and for 6-deoxyhexoses (Dische \& Shettles, 1948) were made without preliminary hydrolysis, but were negative with these walls.

Acetate was measured enzymically after hydrolysis of walls, using a test kit (citrate synthase and acetyl coenzyme A synthetase) from Boehringer Mannheim. 
Ammonia was measured as described by Tetlow \& Wilson (1961). Phosphorus was determined after ashing walls, as described by Ames (1966).

Nitrogen and sulphur in the acidic polymer were assessed qualitatively after fusion with sodium metal (Cohen, 1949).

Chemicals and enzymes. Unlabelled 2,6-diaminopimelic acid (mixed isomers) was chemically synthesized (Saleh \& White, 1976). Lysozyme (egg-white), glucose oxidase and peroxidase (for assay of glucose) and $\alpha$-amylase (bacterial) were all from Sigma.

Radioisotopes and counting. D-(U- $\left.{ }^{14} \mathrm{C}\right] \mathrm{Glucose}$ and 2,6-diamino[G$\left.{ }^{3} \mathrm{H}\right]$ pimelic acid (mixed isomers) were from Amersham. All measurements of radioactivity were by liquid scintillation counting in Cocktail T (BDH)

\section{Results}

\section{Chemical assays with wall material}

When $B$. megaterium NCIB 7581 is grown with glucose as major source of carbon, granules of poly $\beta$-hydroxybutyrate are seen in the cytoplasm. Some of these granules remain trapped within the isolated walls and contribute to their weight, although the granules are not really a part of the wall structure. Chemical analysis (see Methods) demonstrated that about $5 \%(w / w)$ of the material isolated as walls was poly $\beta$-hydroxybutyrate. In all the experiments described below the walls were used without extracting the granules, as they caused no apparent interference in assays, and could be removed by centrifuging after walls were digested with lysozyme or hydrolysed with dilute acid.

Approximately $55 \%(\mathrm{w} / \mathrm{w})$ of the wall may be peptidoglycan (Table 1), which was estimated by assay (amino-acid analyser) of its major constituent amino acids (alanine, glutamate and diaminopimelate) in acidhydrolysed material (Day \& White, 1977). If this is indeed the correct proportion of peptidoglycan and if all the acetate is derived from $\mathrm{N}$-acetyl-groups of hexosamines in the wall, then the hexosamines (particularly muramic acid) must be underestimated.

Table 1. Components of the solid isolated as the wall of B. megaterium NCIB 7581

\begin{tabular}{lcc}
\hline \hline \multicolumn{1}{c}{ Material assayed } & $\begin{array}{c}\mu \mathrm{mol} \\
(\mathrm{mg} \mathrm{wall})^{-1}\end{array}$ & $\begin{array}{c}\mu \mathrm{g} \\
\left(\mathrm{mg} \mathrm{wall}^{-1}\right.\end{array}$ \\
\hline Glucosamine & 0.39 & 63 \\
Muramic acid & $0 \cdot 25$ & 58 \\
Diaminopimelic acid & $0 \cdot 50$ & 86 \\
Alanine & 0.93 & 66 \\
Glutamic acid & $0 \cdot 48$ & 62 \\
Acetic acid & 1.5 & 63 \\
Glucose & 0.30 & 49 \\
Protein & - & 100 \\
Poly $\beta$-hydroxybutyrate* & - & 50 \\
\hline
\end{tabular}

* The poly $\beta$-hydroxybutyrate is present as trapped granules and is not part of the structure of the wall.
Protein was also present even though the walls had been incubated with trypsin during their isolation. The amino-acid analyser showed that the acid-hydrolysates contained numerous amino acids, each at a concentration about one-tenth that of the individual major amino acids of this peptidoglycan. Walls were boiled in $1 \mathrm{M}-\mathrm{NaOH}$ and then assayed for protein by the Lowry method, against standards of bovine serum albumin which had been similarly heated with alkali. About $10 \%(w / w)$ of the wall appeared to be protein, but the estimate may be unreliable as this protein could be chemically very different from the standard.

Neither phosphorus nor uronic acids were found by chemical assay in walls of $B$. megaterium NCIB 7581 . Assays for hexoses (on unhydrolysed walls) gave a yield of coloured product equivalent to $0.35 \mu \mathrm{mol}$ glucose $(\mathrm{mg} \text { wall })^{-1}$. Glucose was measured enzymically in hydrolysates of walls prepared by heating at $100{ }^{\circ} \mathrm{C}$ for various times with $\mathrm{HCl}$ of different concentrations. The maximum yield (obtained after $1 \mathrm{~h}$ with $2 \mathrm{M}-\mathrm{HCl}$ ) was $0.30 \mu \mathrm{mol}(\mathrm{mg} \mathrm{wall})^{-1}$, so that all the carbohydrate detected in the phenol/sulphuric acid assay was probably glucose. Galactose was not detectable by enzymic assay. Paper chromatography of the hydrolysate (solvents A, B) showed a spot (detected with $p$-anisidine) in the position of a glucose marker, and considerably fainter spots with $R_{\text {glucose }}$ values of approx. 0.5 and 0.3 in solvent A. The faster moving of these two latter spots migrated to the same position as a marker of glucosamine, but none of the tested markers moved as slowly as the second spot. Longer times of hydrolysis did not decrease the intensity of this unidentified spot, which was presumed, therefore, not to be an oligosaccharide, nor did any additional spots appear. Incubation of walls with $\alpha$ amylase (in $0.025 \mathrm{M}$-phosphate buffer, $\mathrm{pH} 6.8$ at $37^{\circ} \mathrm{C}$ ) failed to remove any of the glucose (cf. White \& Gilvarg, 1977), so that it was unlikely to be present in the form of glycogen; rather it seemed that the glucose might be part of the accessory polymer. At first, the material tentatively identified as glucosamine was assumed to originate solely from the peptidoglycan. Later work (see below) showed that this was not the case.

Walls of the mutant GW1 gave analytical data that were similar in all respects to those described above for the parent strain.

\section{Separation of the products of lysozyme-digestion of walls}

The action of lysozyme on a bacterial wall ought to lead to hydrolysis of the peptidoglycan into relatively small, water-soluble oligosaccharides. When the rigid insoluble component of the wall is thus dissolved, other polymers (which may be covalently linked to the peptidoglycan but 
not degraded by lysozyme) might also pass into solution as high mol. mass material that can be separated from the unattached fragments of peptidoglycan. However, a polymer isolated in this way will probably have a small piece of peptidoglycan still joined covalently to it.

Lysozyme-digests of walls of strain 7581 were eluted with ammonium acetate buffer, pH 6.5 (usually $0.02 \mathrm{M}$ ) through columns of Sephadex of various grades. The best separation into two peaks (peak 1, of higher mol. mass, being much richer in anthrone-positive material and containing less diaminopimelate) came from Sephadex G-100. Digests of doubly labelled sacculi (see Methods) of the mutant GW1 were eluted through this column. Comparison of the amounts of ${ }^{14} \mathrm{C}$ in the two peaks showed that the higher mol. mass substance(s) made up about $30 \%(\mathrm{w} / \mathrm{w})$ of the material dissolved by lysozyme. Most $(75 \%)$ of the ${ }^{3} \mathrm{H}$ counts (present only in residues of diaminopimelate) were in the peak (2) of lower mol. mass. Passage through Sephadex G-100 was therefore generally used as the first step in isolating the accessory polymer(s) from an enzymic digest of walls.

Fractions making up peak 1 were combined and samples of this solution were applied at various $\mathrm{pH}$ values $(5,6,7,8)$ to small columns of DEAE-cellulose, which were eluted with buffer $(0 \cdot 1 \mathrm{M})$ of the same $\mathrm{pH}$ values. All of the anthrone-positive material from peak 1 emerged very quickly at $\mathrm{pH} 5$ or 8 , but was retained at pH 6 or 7, which meant that it was present as a component of weakly acidic molecules. Gradient elution at $\mathrm{pH} 7$ (ammonium acetate buffer, $0 \cdot 1$ to $3 \mathrm{M}$ ) gave a single peak (called 3 ) of anthrone-positive material which emerged in approx. $0.5 \mathrm{M}$-buffer. The ratio of $\left[{ }^{3} \mathrm{H}\right] \mathrm{di}-$ aminopimelate to anthrone-positive material in peak 3 was the same as in peak 2 . These observations suggested that there was a single accessory polymer in the digest of wall, and that a piece of peptidoglycan remained joined to this acidic polymer. The chromatography on DEAEcellulose did not achieve any purification of the acidic polymer, and so was not used routinely in its isolation. Instead the combined peak 1 fractions (from Sephadex G-100) were freeze-dried and taken up in a small volume of water, to which was added 3 vols ethanol, with mixing; addition of a few drops of $1 \mathrm{M}-\mathrm{HCl}$ caused an immediate precipitate, which was left to settle overnight at $2{ }^{\circ} \mathrm{C}$. The solid was collected by centrifuging, and was redissolved in water, from which it was freeze-dried. This material was called 'acidic polymer'.

\section{Extraction of walls with acid}

Accessory polymers are very often isolated from bacterial walls by extraction with TCA, although this method may decrease the size of the polymer by causing its partial breakdown. Incubation of walls in TCA $(5 \%, w / v)$ or
$0.1 \mathrm{M}-\mathrm{HCl}$ at $37{ }^{\circ} \mathrm{C}$ for $4 \mathrm{~d}$ extracted into solution $89 \%$ and $70 \%$ respectively of the total anthrone-positive material of the walls. After removal of acid the two extracts were separately eluted through a column of Sephadex G-25. Anthrone-positive material emerged in each case as a broad peak, with the TCA extract having the greater retention volume (i.e. lower molecular size). Unlike that of the lysozyme-extracted polymer, the elution volumes of both peaks were greater than the void volume of the column. Little $(<4 \%)$ of the anthronepositive material extracted by TCA and passed through Sephadex G-25 was precipitable from acidic alcoholic solution even though it was at a concentration that would be sufficient for the lysozyme-extracted material to be deposited in high yield.

Extraction of walls with $0.1 \mathrm{M}-\mathrm{HCl}$ for $24 \mathrm{~h}$ at $60^{\circ} \mathrm{C}$ released $86 \%$ of the total anthrone-positive material (39\% of the weight of the wall); similar extraction of ${ }^{14} \mathrm{C}$ labelled sacculi liberated $40 \%$ of the total radioactivity. The material that was released (from unlabelled walls) was obtained as a pale brown residue after removal of acid, passage through Sephadex G-25 and drying. It was hydrolysed $\left(6 \mathrm{M}-\mathrm{HCl}\right.$ at $105^{\circ} \mathrm{C}$ for $\left.18 \mathrm{~h}\right)$ and tested for diaminopimelate by chromatography and colorimetric assay: none was found. Thus, the acid-extraction seemed to have removed peptidoglycan from the accessory polymer. Later assays on other hydrolysates showed that equimolar quantities of the major components of the accessory polymer glucose, glucosamine and 3-amino3,6-dideoxyhexose (see accompanying paper: Bishop \& White, 1993) were present in the extracted material.

\section{Properties of the acidic polymer from lysozyme-digests}

Titration. An aqueous solution of the polymer had an initial $\mathrm{pH}$ value of $3 \cdot 2$. Buffering capacity was shown by the polymer at alkaline $\mathrm{pH}$ values $[2.9 \mathrm{mmol}$ of $\mathrm{NaOH}$ needed ( $\mathrm{g}$ polymer $)^{-1}$ to titrate to $\mathrm{pH} 10$ ], presumably because of acidic groups in the molecule. Some of this acidity could be due to free carboxylic acid groups of amino acids present in the attached peptidoglycan [alanine (-COOH terminal), glutamate and diaminopimelate]. However, the total acidity caused by these substances must be $<1 \mathrm{mmol}$ (g polymer) ${ }^{-1}$ because the $0.32 \mathrm{mmol}$ of diaminopimelate and of glutamate in $1 \mathrm{~g}$ of polymer might each provide up to 0.32 mequiv. of acidity, while alanine should give less owing to the loss of free - $\mathrm{COOH}$ groups on alanine residues whenever crosslinking occurred. The excess acidity $\left(>1.9\right.$ mequiv. $\mathrm{g}^{-1}$ ), not caused by peptidoglycan, suggests that about $1 \mathrm{~mol}$ of $-\mathrm{COOH}$ (or other acidic functions) is present in approximately $500 \mathrm{~g}$ of polymer.

Composition. The acidic polymer was assayed enzymically (after acid hydrolysis) for glucose and galactose, 


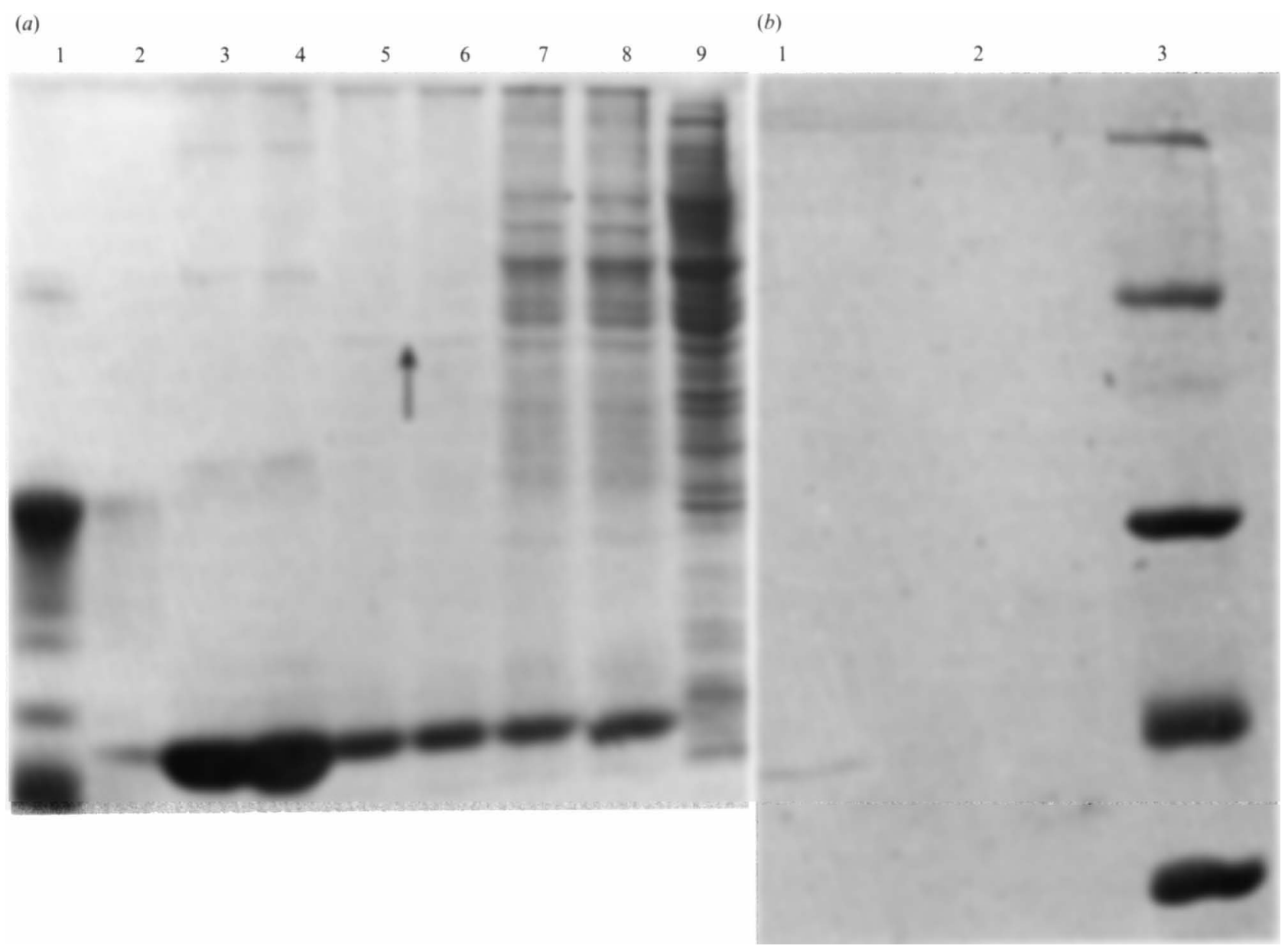

Fig. 1. SDS-PAGE of protein from walls of B. megaterium NCIB 7581 on a $10 \%$ polyacrylamide gel, stained with Coomassie Brilliant Blue. (a) Track 1, trypsin (bovine) $16 \mu \mathrm{g}$; track 2, buffer; tracks 3 and 4, lysozyme (egg-white) $5 \mu \mathrm{g}$ and $6.5 \mu \mathrm{g}$; tracks 5 and 6 , trypsinized walls, digested with lysozyme, $250 \mu \mathrm{g}$ and $325 \mu \mathrm{g}$ (the arrow tip indicates the position of the trypsin-resistant protein); tracks 7 and 8 , walls not trypsinized, digested with lysozyme, $125 \mu \mathrm{g}$ and $162 \mu \mathrm{g}$; track 9 , cytoplasmic contents. In tracks 5 and 6 the dense band corresponds to the position of lysozyme. (b) Track 1, trypsinized walls, lysozyme-digested; track 2, trypsinized walls, lysozymedigested, then again trypsinized; track 3, mol. mass standards (see Methods.).

and hexose was assessed by the phenol/sulphuric acid and the anthrone procedures. Paper chromatograms (solvent A) of acid hydrolysates showed three spots (after $\mathrm{AgNO}_{3}$ or $p$-anisidine) in the same positions and with similar relative intensities as were seen in the hydrolysates of complete walls described above. Glucosamine (specific assay of Cessi \& Piliego, 1960) and glucose were present in about 1:1 molar proportions, while almost no muramic acid was detected (assay of Stewart-Tull, 1968). Galactosamine (assay of Cessi \& Piliego, 1960) was also absent. Possibly muramic acid had been destroyed during hydrolysis; nevertheless, the amount of diaminopimelate in the polymer did not indicate a quantity of peptidoglycan sufficient to furnish very much muramic acid and glucosamine.

The release of free glucose (measured enzymically) from a solution of the polymer $\left(5 \mathrm{mg} \mathrm{ml}^{-1}\right)$ was examined after various times of incubation with $2 \mathrm{M}-\mathrm{HCl}$ at $100{ }^{\circ} \mathrm{C}$ in order to find optimum conditions for acid hydrolysis. Maximum liberation $\left(0.87 \mu \mathrm{mol} \mathrm{mg}^{-1}\right)$ was after $2 \mathrm{~h}$, and comprised $80 \%$ of the total hexose content measured with anthrone (glucose as standard). The polymer was also hydrolysed for various times in $2 \mathrm{M}-$ and $3 \mathrm{M}-\mathrm{HCl}$ at $100^{\circ} \mathrm{C}$ and then assayed for hexosamine (Levvy \& McAllan, 1959) and $N$-acylglucosamine; these latter data were obtained by omitting the acetic anhydride reagent from the assay procedure so that unsubstituted glucosamine would give no colour. After $10 \mathrm{~min}$ in $2 \mathrm{M}$ $\mathrm{HCl}, 72 \%$ of the maximum glucosamine value had been reached, and of this, most $(86 \%)$ was still acylated. Maximum release of glucosamine $\left(0.85 \mu \mathrm{mol} \mathrm{mg}^{-1}\right)$ was again in $2 \mathrm{M}-\mathrm{HCl}$ after $2 \mathrm{~h}$, while $N$-acylation had become negligible within $80 \mathrm{~min}$. This rapid liberation of glucosamine monomers by acid hydrolysis differs from the 
relative resistance to acid hydrolysis that is shown by polymer chains which are made up solely of aminosugar units, such as chitin or peptidoglycan.

By fusion with sodium (see Methods) the dried acidic polymer was found to contain nitrogen, but no sulphur. No uronic acid was revealed by colorimetric assay or by paper chromatography of hydrolysates. However, aminouronic acids are sometimes found in accessory polymers (e.g. Perkins, 1963) and such acids are not easily recognized because there is no specific method for their detection. Acid hydrolysis breaks down their molecules, so that no characteristic spot is seen on chromatograms, but ammonia is liberated from the aminouronic acid. For this reason the acidic polymer was hydrolysed with $2 \mathrm{M}-\mathrm{HCl}$ for various times at $100^{\circ} \mathrm{C}$ and the hydrolysates, without any preliminary drying, were assayed for ammonia. None of the hydrolysates contained any more ammonia than was present in the solution of polymer before hydrolysis. Consequently, aminouronic acids were absent.

Acetate was present in these undried hydrolysates, being approximately equimolar with the glucosamine plus muramate, whereas no acetate was released after a solution of the polymer had been kept at $\mathrm{pH} 10$ overnight at $37^{\circ} \mathrm{C}$, under which conditions $O$-acetyl-groups should be set free. Hence, these two aminosugars seem to occur as $\mathrm{N}$-acetyl-derivatives in the polymer.

Glucose, glucosamine, acetate and fragments of peptidoglycan do not account for all the weight of the isolated accessory polymer. Other components remained to be identified. Further work to this end is reported in the accompanying paper (Bishop \& White, 1993).

\section{The protein of the wall}

Incubation with trypsin was routinely used in the isolation of walls because omission of this step led to the presence of many proteins in the solid product finally obtained (Fig. 1 $a$ ). Nevertheless, the trypsinized walls still contained some protein (see above), which could be released into solution by digestion of the walls with lysozyme. The dissolved trypsin-resistant material gave only a single faint band on gel electrophoresis (Fig. $1 b$ ), and comparison with the migration of standards indicated a mol. mass of about $40000 \mathrm{Da}$. The lysozymedigest was next adjusted to $\mathrm{pH} 7$ by addition of disodium hydrogen phosphate, then trypsin (to $100 \mu \mathrm{g} \mathrm{ml}^{-1}$ ) was added and the solution was incubated for $3 \mathrm{~h}$ at $37^{\circ} \mathrm{C}$. Subsequent gel electrophoresis showed only the bands due to lysozyme and trypsin; there was no band at $40000 \mathrm{Da}$, even though the additions of buffer and trypsin had only slightly diluted the lysozyme-digest. The protein that survived the first incubation with trypsin might, therefore, not be intrinsically resistant to hy- drolysis by this enzyme, but might be protected against proteolysis by association with wall material that acted as a barrier to trypsin.

\section{Formation of capsules}

B. megaterium NCIB 7581 forms a capsule that can be made visible by Indian ink, only under certain conditions. In order to produce capsulated bacteria at $37^{\circ} \mathrm{C}$ it was necessary to supplement solid medium $\mathrm{A}$ (glucose as major carbon source) with acid-hydrolysed casein (Difco 'vitamin-free'; $1 \mathrm{~g} \mathrm{l}^{-1}$ ). No capsules were seen at $37^{\circ} \mathrm{C}$ on organisms from liquid cultures in medium $\mathrm{A}$, whether or not it was supplemented.

Capsular material was isolated by both of the procedures described in Methods. No positive reaction was given in the anthrone- or phenol/sulphuric acid tests for carbohydrate, and colour development in the Lowry assay for protein was very weak (equivalent to $<100 \mu \mathrm{g}$ protein per mg capsular material). Paper chromatography of hydrolysates (solvent F) showed that four principal ninhydrin-positive substances were present, in the positions of markers of alanine, glutamate, leucine and methionine; the spot in the position of glutamate was not especially intense, and diaminopimelate was absent, while no spots were revealed by $p$-anisidine, which reacts with many sugars. Thus, the capsule seems to consist of one or more polypeptides, free of peptidoglycan, but it is not solely polyglutamate. The composition of the capsule was quite unlike that of the trypsin-resistant protein of the wall, which after hydrolysis gave a continuous streak of numerous unresolved amino acids on paper chromatography (solvent F).

\section{Discussion}

The walls of $B$. megaterium used in this study were isolated by exploiting their insolubility, sedimentability and resistance to proteolysis. It is commonly supposed that the solid obtained in this way from Gram-positive bacteria does represent the firm, shape-defining layer of the organisms, which is external to the cytoplasmic membrane. In this material, peptidoglycan is believed to form the rigid, insoluble matrix, to which other components of the wall proper are covalently linked. A single 'accessory polymer' (usually teichoic acid or teichuronic acid) and peptidoglycan often make up together nearly all of the weight of the wall. Frequently, however, there are difficulties in accounting for all of the weight of the wall as identified substances, and in deciding what molecules really are parts of the structure of the wall rather than merely loosely adherent foreign polymers.

These problems are illustrated by the present work. 
Poly $\beta$-hydroxybutyrate contributes to the weight of the isolated 'wall' but the granules are visible by phase contrast microscopy and are obviously intracellular bodies that stick inside the walls. Protein also is present, and it is much more difficult to determine whether this is extraneous or a genuine part of the wall. The apparent protection of this protein by the insoluble wall against digestion by trypsin suggests that there is a close association between the protein and the wall. The fact that the protein gives a single band on gel electrophoresis might imply that it is a specific unit of the wall and is not random contamination from the cytoplasm. Protein is not generally a major component of Gram-positive walls; indeed, the usual methods of isolation of walls (as in the present work) include treatment with a proteolytic enzyme, which ensures that little protein will be present in the final product. Nevertheless, protein certainly is a part of some Gram-positive walls (e.g. Fox, 1974), and it is often supposed that autolytic enzymes exist in a very near relationship to the bacterial wall.

A single acidic polymer does appear to be covalently linked to peptidoglycan, and these two polymers make up most of the weight of the wall. Here the difficulty lies in identifying and measuring all of the monomers that make up the acidic polymer. Later work (accompanying paper: Bishop \& White, 1993) has led to the recognition that this polymer consists very largely of equimolar quantities of glucose, $\mathrm{N}$-acetylglucosamine and an $\mathrm{N}$ lactyl-3-amino-3,6-dideoxyhexose.

Every preparation of walls or sacculi used in this investigation was made from organisms that were grown in liquid culture at $37^{\circ} \mathrm{C}$, under which conditions no capsules can be seen microscopically. Furthermore, capsular material can be removed by repeated washing of the bacteria (unpublished observations) and so it is very unlikely that such material was present in the final isolates of walls, which were washed many times during their purification.

Although it has not been fractionated, the capsule consists solely of polypeptide(s). Baumann-Grace \& Tomcsik (1957) found, with a different strain of $B$. megaterium, that two types of capsular material, polysaccharide and polypeptide, could be present together on different regions of a single organism. Thorne (1956) reported, with other species of Bacillus, that the capsule was entirely polypeptide. With strain NCIB 7581 , the presence of a capsule is strikingly dependent on composition of the medium, temperature of incubation and age of culture.

A.H.B. received a studentship from the SERC and C.W.I.D. was supported by a research grant (GR/A38663) from the SERC. The mutant GW1 was isolated by Mr Allen Giles during his undergraduate research project, and preliminary studies on the capsular material were done by Miss Susan Smith in her project. Miss Lorna Young has given excellent technical assistance at many stages of this work. We are very grateful to those people for their help.

\section{References}

AL-SSUM, R. M. \& WhitE, P. J. (1977). Effects of biotin-deficiency on growth, morphology and sporulation in Bacillus megaterium NCIB 7581. Journal of General Microbiology 99, 343-351.

Ames, B. N. (1966). Assay of inorganic phosphate, total phosphate and phosphatases. Methods in Enzymology 8, 115-118.

BAILEY, R. W. (1969). Carbohydrates. In Data for Biochemical Research, 2nd edn, pp. 539-550. Edited by R. M. C. Dawson, D. C. Elliott, W. H. Elliott \& K. M. Jones. Oxford: University Press.

Baumann-Grace, J. B. \& Tomcsik, J. (1957). The surface structure and serological typing of Bacillus megaterium. Journal of General Microbiology 17, 227-237.

BERgMeYer, H.-U. \& BerNT, E. (1963). Determination with glucose oxidase and peroxidase. In Methods of Enzymatic Analysis, 1st edn, pp. 123-130. Edited by H.-U. Bergmeyer. New York \& London: Academic Press.

Bishop, A. H. \& WhITE, P. J. (1993) Composition of an unusual accessory polymer containing $N$-lactyl-3-amino-3,6-dideoxyhexose in walls of Bacillus megaterium NCIB 7581. Journal of General Microbiology 139, 2731-2738.

BitTER, T. \& MutR, H. M. (1962). A modified uronic acid carbazole assay. Analytical Biochemistry 4, 330-334.

Cessi, C. \& Piliego, F. (1960). Determination of amino sugars in presence of amino acids and glucose. Biochemical Journal 77, 508-510.

CoHen, J. B. (1949). Practical Organic Chemistry, 3rd edn, pp. 4-5. London: Macmillan \& Co.

DAY, A. \& WhITE, P. J. (1977). Enzymic assays for isomers of 2,6diaminopimelic acid in walls of Bacillus cereus and Bacillus megaterium. Biochemical Journal 161, 677-685.

DisCHE, Z. \& SHETTLES, L. B. (1948). A specific color reaction of methylpentoses and a spectrophotometric micromethod for their determination. Journal of Biological Chemistry 175, 595-603.

Dubois, M., Gilles, K. A., Hamilton, J. K., Rebers, P. A. \& SMith, F. (1956). Colorimetric method for determination of sugars and related substances. Analytical Chemistry 28, 350-356.

Fox, E. N. (1974). M proteins of group A streptococci. Bacteriological Reviews 38, 57-86.

HAYASh, H., ARAKI, Y. \& ITo, E. (1973). Occurrence of glucosamine residues with free amino groups in cell wall peptidoglycan from bacilli as a factor responsible for resistance to lysozyme. Journal of Bacteriology 113, 592-598.

Herbert, D., Phipps, P. J. \& Strange, R. E. (1971). Chemical analysis of microbial cells. Methods in Microbiology 5B, 209-344.

LAEMMLI, U. K. (1970). Cleavage of structural proteins during the assembly of the head of bacteriophage T4. Nature, London 227, 680-685.

LeVvy, G. A. \& McAllan, A. (1959). The $N$-acetylation and estimation of hexosamines. Biochemical Journal 73, 127-132.

Milner, H. W., Lawrence, N. S. \& French, C. S. (1950). The colloidal dispersal of chloroplast material. Science 111, 633-634.

MORRISSEY, J. H. (1981). Silver stain for protein in polyacrylamide gels: a modified procedure with enhanced uniform sensitivity. Analytical Biochemistry 117, 307-310.

Perkins, H. R. (1963). A polymer containing glucose and aminohexuronic acid isolated from the cell walls of Micrococcus lysodeikticus. Biochemical Journal 86, 475-483.

Rhuland, L. E., Work, E., Denman, R. F. \& Hoare, D. S. (1955). The behaviour of isomers of $\alpha, \varepsilon$-diaminopimelic acid on paper chromatograms. Journal of the American Chemical Society 77, 48444846.

SALEH, F. \& White, P. J. (1976). Use of auxotrophic mutants to isolate LL- and DD-isomers of 2,6-diaminopimelic acid. Journal of General Microbiology 96, 253-261.

SALEH, F. \& WhITE, P. J. (1979). Metabolism of DD-2,6-diaminopimelic acid by a diaminopimelate-requiring mutant of Bacillus megaterium. Journal of General Microbiology 115, 95-100. 
SteWART-TULL, D. E. S. (1968). Determination of amino sugars in mixtures containing glucosamine, galactosamine and muramic acid. Biochemical Journal 109, 13-18.

TetLow, J. A. \& Wilson, A. L. (1964). An absorptiometric method for determining ammonia in boiler feed-water. Analyst 89, 453-465.

Thorne, C. B. (1956). Capsule formation and glutamyl polypeptide synthesis by Bacillus anthracis and Bacillus subtilis. Symposia of the Society for General Microbiology 6, 68-80.

WHITE, P. J. (1972). The nutrition of Bacillus megaterium and Bacillus cereus. Journal of General Microbiology 71, 505-514.
WHITE, P. J. (1977). A survey for the presence of teichuronic acid in walls of Bacillus megaterium and Bacillus cereus. Journal of General Microbiology 102, 435-439.

White, P. J. \& Gilvarg, C. (1977). A teichuronic acid containing rhamnose from cell walls of Bacillus megaterium. Biochemistry (A.C.S.) 16, 2428-2435

WORK, E. (1957). Reaction of ninhydrin in acid solution with straight chain aminoacids containing two amino groups and its application to the estimation of $\alpha, \varepsilon$-diaminopimelic acid. Biochemical Journal 67, 416-423. 